\title{
Lipid profile of children with glycogen storage disease
}

\author{
Tatyana Victorovna Strokova', Elena Vyacheslavovna Pavlovskaya', Andrey Igorevich Zubovich ${ }^{1}$, Yurgita \\ Ruslanovna Varaeva', Natalia Valerievna Polenova', Elena Nikolaevna Livantsova', Madlena Enverovna \\ Bagaeva', Alexander Gennadievich Surkov', Svetlana Dmitrievna Kosyura ${ }^{1,2}$, Antonina Vladimirovna \\ Starodubova ${ }^{1,2}$
}

'Department of Pediatric Gastroenterology, Hepatology and Nutrition, Nutrition Clinic of Federal Research Centre of Nutrition, Biotechnology and Food Safety, Moscow 115446, Russia.

${ }^{2}$ Department of Personalized Therapy and Nutrition, Nutrition Clinic of Federal Research Centre of Nutrition, Biotechnology and Food Safety, Moscow 115446, Russia.

Correspondence to: Dr. Yurgita Ruslanovna Varaeva, Junior Research Fellow of Department of Personalized Therapy and Nutrition, Nutrition Clinic of Federal Research Centre of Nutrition, Biotechnology and Food Safety, Kasirskoe shosse 21, Moscow 115446, Russia. E-mail: yurgitavaraeava@gmail.com

How to cite this article: Strokova TV, Pavlovskaya EV, Zubovich Al, Varaeva YR, Polenova NV, Livantsova EN, Bagaeva ME, Surkov AG, Kosyura SD, Starodubova AV. Lipid profile of children with glycogen storage disease. Vessel Plus 2019;3:16. http://dx.doi.org/10.20517/2574-1209.2019.08

Received: 3 Dec 2018 First Decision: 5 Feb 2019 Revised: 11 Feb 2019 Accepted: 12 Feb 2019 Published: 10 May 2019

Science Editor: Alexander N. Orekhov Copy Editor: Cai-Hong Wang Production Editor: Huan-Liang Wu

\begin{abstract}
Aim: To determine the lipid profile patterns in children with different types of glycogen storage disease (GSD).
\end{abstract}

Methods: The study included 62 children with GSD (43 boys, 19 girls), mean age 8.29 years. All patients underwent anthropometry, assessment of physical development, lipid profile analysis.

Results: The children were divided into three groups depending on the type of GSD. Nineteen children (31\%) had type I GSD (Group 1), 16 (26\%) - type III (Group 2) and 27 (43\%) - types VI and IX (Group 3). Dyslipidemia of varying severity was more specific to patients with type I and III GSD. Higher levels of triglycerides were associated with type I GSD, while higher levels of LDL cholesterol were common to type III GSD $(P<0.05)$ No changes in the lipid profile were observed in 18 (29\%): one with type I, 4 with type III, and 13 with types VI and IX.

Conclusion: Lipid metabolism disorders were detected in $71 \%$ of children with GSD, especially with types I and III. The elevated levels of total cholesterol and LDL cholesterol are associated with the early progression of atherosclerosis and an increased cardiovascular risk in the general population. But there is a lack of evidence of a link between lipid metabolism 
disorders detected in childhood and an increased risk of cardiovascular diseases in patients with GSDs. More studies needed to investigate this issue.

Keywords: Lipid profile, glycogen storage disease, children, triglycerides, LDL cholesterol

\section{INTRODUCTION}

Glycogen storage disease (GSD, glycogenosis, dextrinosis) is a common term for a group of hereditary metabolic disorders associated with impaired glycogen metabolism. The prevalence of GSD varies from one case per 20,000 to 300,000 births depending on the type of disease ${ }^{[1]}$.

The major part of GSDs has an autosomal recessive inheritance (e.g., type IX is X-linked recessive disorder) and implemented through specific enzyme deficiencies. Furthermore, some cases of simultaneous several enzymes failure have been described. Defects in synthesis enzymes, as well as glycogen utilization enzymes, can be observed depending on the GSD type. Genetic disturbances of glycogen metabolism lead to the accumulation of normal and/or pathologically changed glycogen in internal organs and tissues. The liver, heart, skeletal muscles and blood cells are affected in GSD I (von Gierke disease), III (Cori or Forbes disease), VI (Hers disease), VII (Tarui disease), VIII and IX types ${ }^{[2]}$. The pronounced metabolic changes cause growth and developmental delay at an early age ${ }^{[2]}$.

The cardiac pathology in GSDs especially in type II (Pompe disease) is well studied ${ }^{[3]}$. Among other types, the most common cardiovascular (CV) disorders are found in children with type III GSD. Myocardial involvement in GSD is performed by left ventricular hypertrophy, less frequently cardiomegaly, or isolated right ventricular hypertrophy and, in rare cases, life-threatening arrhythmia and hypertrophic cardiomyopathy as non-compact ventricular myocardium ${ }^{[4]}$. Pulmonary arterial hypertension is another $\mathrm{CV}$ complication of $\mathrm{GSD}^{[5,6]}$.

The crucial mechanism of CV complications in GSD is dyslipidemia. GSD-associated lipid disorders indicate close interactions between the metabolism of carbohydrates and lipids in these patients ${ }^{[7]}$. In case of such severe metabolic disorders as GSDs, especially types I and III, affect lipid metabolism in early childhood.

According to the Rake study, hypercholesterolemia and hypertriglyceridemia are more common in type I GSD, particularly subtype $\mathrm{Ia}^{[8]}$. Furthermore, pancreatitis and cholelithiasis are prevalent complications of hyperlipidemia in GSD. Moreover, these patients characterised by the higher relationship of high triglyceride levels $(>5.6 \mathrm{mmol} / \mathrm{L})$ with hepatic adenoma development ${ }^{[\rho]}$.

Hypertriglyceridemia in GSD type I occurs as a result of a number of reasons. First, a violation of gluconeogenesis leads to the accumulation of fatty acid precursors, from which triglycerides are subsequently synthesized. Secondly, a decreased lipoprotein lipase activity causes disturbances in physiological lipolysis and a decrease in the clearance of triglycerides. In addition, the conditions described above can be exacerbated by a chronically low level of insulin, which normally inhibits the synthesis of triglyceride-rich particles in the liver ${ }^{[10,11]}$. Finally, a fatty liver is a common condition in patients with GSD I as a consequence of excess fatty acid transport from the adipose tissue to the liver and increased lipogenesis de novo ${ }^{[12]}$. Increased cholesterol synthesis in combination with disturbances of lipoprotein and triglyceride elimination leads to severe hypercholesterolemia and hypertriglyceridemia in patients with GSD I ${ }^{[13,14]}$.

In GSD III, hypertriglyceridemia is detected in $67 \%$ of patients, while only one-third demonstrates hypercholesterolemia. In general, lipid disorders are not as common comparing to GSD I ${ }^{[15]}$. 
The impact of oxidized lipoproteins on atherogenesis is well known ${ }^{[16]}$. The role of oxidative stress and total antioxidant protection in patients with GSD I was examined in a number of studies. In one study, total reactive antioxidant potential was compared between children with GSD, diabetes, and familial hypercholesterolemia. This biomarker was much higher among GSD patients ${ }^{[17]}$.

Some studies demonstrated the development of premature atherosclerosis and an increased risk of CV complications associated with $\mathrm{GSD}^{[18,19]}$, whereas others did not reveal the association of GSD with premature atherosclerosis ${ }^{[1,20]}$. Moreover, it was found that LDL-cholesterol particles are paradoxically more resistant to oxidative stress in patients with GSD I compared to the control group ${ }^{[21]}$.

A series of studies show the connection between high cholesterol levels in children and adolescents in the general population and the risk of atherosclerosis and CV complications in adult life ${ }^{[2]}$. However, despite the fact of the existence of dyslipidemia in GSD has been known for several decades, the need for medical treatment of lipid disorders in GSD is still disputable.

Fibrates, statins, niacin, bile acid sequestrants, ezetimibe, lomitapide, phytosterols, fish oil, etc. are currently used to correct lipid disorders in adults. The issue of prescribing these medicines to children remains controversial. Apparently, lipid-lowering therapy should be prescribed if there are strict indications, when diet therapy does not eliminate high levels of blood lipids, threatening the development of acute pancreatitis or atherothrombotic complications ${ }^{[23]}$.

Thus, the aim of our study was to determine lipid profile patterns in children with different types of glycogen storage disease.

\section{METHODS}

The study included 62 children with GSD (43 boys, 19 girls), mean age 8.29 years. All patients underwent anthropometry including weight, height adjusted as $Z$-score to the age with the calculation of body mass index $Z$-score and percentiles. The assessment of physical development for overweight and obesity was carried out using the WHO Anthro and AnthroPlus programs. Fasting total cholesterol, HDL cholesterol, LDL cholesterol and triglycerides plasma levels were analyzed by Konelab Prime 60i auto-analyzer (Thermo Scientific, Wilmington, DE, USA) with the internal age-adjusted normal range. Dyslipidemia was defined as any abnormal total cholesterol, HDL cholesterol, LDL cholesterol or/and triglycerides plasma levels. Statistical analysis was performed using Statistica for Windows 6.0 (StatSoft Inc., USA). The statistical significance level was taken as sufficient for $P<0.05$.

The study was conducted in agreement with the Declaration of Helsinki, GCP. The special approval from the Independent Local Board of Ethics Committee was received.

\section{RESULTS}

The children were divided into three groups depending on the type of GSD. Nineteen children (31\%) had type I GSD (Group 1), 16 (26\%) - type III (Group 2) and 27 (43\%) - types VI and IX (Group 3). The groups were comparable in age. In the group of children with type VI and IX GSD, boys prevailed, since the vast majority of patients had type IX GSD, which is characterized by the X-linked pattern.

Overweight and obesity were found in 10.5\% of children in Group 1, 6.3\% in Group 2 and 11.1\% in Group 3. Weight deficit was observed in $21 \%, 12.5 \%$, and $14.8 \%$, respectively.

Lipid profile disorders were detected in 44 (71\%) of 62 children. Dyslipidemia of varying severity was more specific to patients with type I and III GSD. Higher levels of triglycerides were associated with type I GSD, 
Table 1. Lipid profile of children with GSD $(n=62)$

\begin{tabular}{lllc}
\hline GSD type & $\begin{array}{c}\text { Total } \\
(\boldsymbol{n}=\mathbf{6 2})\end{array}$ & $\begin{array}{c}\text { Type I } \\
(\boldsymbol{n}=\mathbf{1 9})\end{array}$ & $\begin{array}{c}\text { Type III } \\
(\boldsymbol{n}=\mathbf{1 6})\end{array}$ \\
\hline Cholesterol, mmol/L & $4.7 \pm 0.2$ & $4.9 \pm 0.5$ & $4.9 \pm 0.3$ \\
HDL cholesterol, mmol/L & $0.6 \pm 0.03$ & $0.8 \pm 0.06$ & $0.8 \pm 0.07$ \\
LDL cholesterol, $\mathrm{mmol} / \mathrm{L}$ & $3.1 \pm 0.1$ & $2.8 \pm 0.2$ & $3.6 \pm 0.3$ \\
Triglycerides, $\mathrm{mmol} / \mathrm{L}$ & $2.2 \pm 0.3$ & $3.9 \pm 0.8$ & $2.05 \pm 0.3$ \\
\hline
\end{tabular}

while higher levels of LDL cholesterol were common to type III GSD $(P<0.05)$ [Table 1]. No changes in the lipid profile were observed in 18 (29\%): one with type I, 4 with type III, and 13 with types VI-IX.

Hypertriglyceridemia and a decrease in the level of HDL cholesterol were most frequently detected [Figures $1 \mathrm{~A}$ and B]. Hypertriglyceridemia was specific to type I and III GSD. At the same time, low HDL cholesterol levels were more common in patients with type I GSD than in patients with type III or type VI-IX GSD.

Hypercholesterolemia was diagnosed in more than one-third of patients with type I and type III GSD, and more than one-third of patients with type III demonstrated high levels of LDL cholesterol [Figure 1C].

Thus, hypercholesterolemia, hypertriglyceridemia and low HDL cholesterol are common to type I GSD, while high levels of LDL cholesterol, hypertriglyceridemia and low HDL cholesterol are typical for type III GSD. For type VI and IX GSD, lipid metabolism disorders were observed less frequently, and the most common changes were a decrease in HDL cholesterol.

\section{DISCUSSION}

Lipid metabolism disorders, including hypercholesterolemia, hypertriglyceridemia, and decreased levels of HDL cholesterol were detected in $71 \%$ of children with GSD. They were mainly observed in patients with types I and III of the disease, in which hypertriglyceridemia often occurred. More than one-third of patients with type I and type III GSD were diagnosed with hypertriglyceridemia, and an equal number of patients with type III GSD had elevated levels of LDL cholesterol. Patients with GSD VI-IX types performed lower rates of lipid disorders.

The elevated levels of total cholesterol and LDL cholesterol are closely associated with the early progression of atherosclerosis and an increased cardiovascular risk in the general population. At the same time, there is still no clear position on hypertriglyceridemia as a risk factor for cardiovascular diseases ${ }^{[24]}$.

According to some studies hypertriglyceridemia can be associated with atherogenesis, firstly, as a marker of some metabolic disorders, secondly, because of the vascular wall macrophages infiltration due to oxidised triglyceride-rich lipoproteins receptor activation ${ }^{[11]}$. There is evidence that elevated triglycerides lead to hypercoagulation through stimulation of a plasminogen tissue activator inhibitor, an increase in the content of VII coagulation factor, and the activation of the transition of prothrombin to thrombin ${ }^{[24]}$. The Hokanson and Austin meta-analysis of prospective studies established that triglyceride levels of up to $5 \mathrm{mmol} / \mathrm{L}(450 \mathrm{mg} / \mathrm{dL})$ predicted the risk of coronary heart disease (CHD), especially in women. Thus, in the Framingham study, the risk of CHD positively correlated with triglycerides levels ${ }^{[25]}$.

According to the Copenhagen Male Study covering 2,906 men aged 52-74 years without CHD, the first myocardial infarction occurred in 229 of them in 8 years of follow-up and the risk of developing CHD increased as the initial triglyceride levels increased ${ }^{[26]}$. A meta-analysis of clinical trials with a total of 46,413 men and 10,864 women examined by Hokanson and Austin showed that triglycerides are an independent risk factor for CHD even after adjusting for HDL cholesterol values ${ }^{[26]}$. 

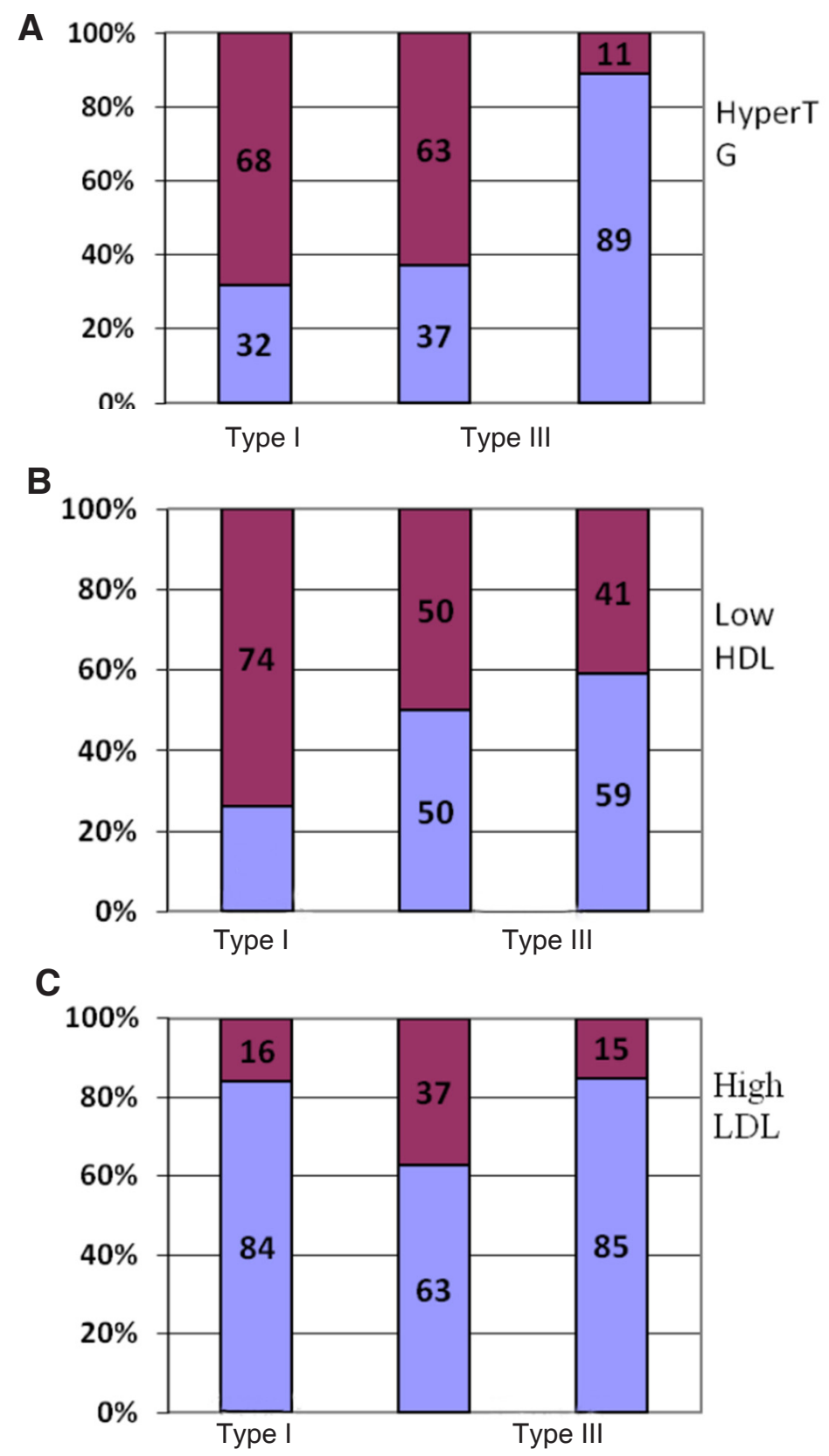

Figure 1. Dyslipidemia patterns in children with different types of GSD ( $n=62)$. 1st column - Type I; 2 nd column - Type III; 3rd column Types VI and IX. Dark purple - abnormal levels; light blue - normal levels. A: Triglycerides; B: HDL cholesterol; C: LDL cholesterol

There is currently no convincing evidence of a link between lipid metabolism disorders detected in childhood and an increased risk of cardiovascular diseases in patients with GSDs. More studies needed to investigate this issue.

\section{DECLARATIONS}

\section{Authors' contributions}

Concept and design: Strokova TV, Pavlovskaya EV, Starodubova AV

Data acquisition: Pavlovskaya EV, Zubovich AI, Bagaeva ME, Surkov AG

Data analysis: Varaeva YR, Polenova NV, Kosyura SD

Manuscript preparation: Varaeva YR, Polenova NV, Livantsova EN

Critical revision and finalizing of the manuscript: Pavlovskaya EV, Varaeva YR, Starodubova AV 


\section{Availability of data and materials}

Authors confirm that the data were strictly obtained from medical records according to the privacy policy and ethics code of our institute.

\section{Financial support and sponsorship}

Research work carried out at the expense of subsidies for public tasks in the framework of the Program of Basic Research of state academies of science for 2013-2020 (0529-2016-0007; 0529-2018-0113).

\section{Conflicts of interest}

All authors declared that there are no conflicts of interest.

\section{Ethical approval and consent to participate}

The study received an approval from the Local Ethic Committee (0529-2016-0007), as it was conducted as a part of the State Program of Basic Research. All procedures were done with accordance to GCP standards and Informed consents from parents or official representatives were received prior to any research procedures.

\section{Consent for publication}

Not applicable.

\section{Copyright}

(c) The Author(s) 2019.

\section{REFERENCES}

1. Ozen H. Glycogen storage diseases: new perspectives. World J Gastroenterol 2007;13:2541-53.

2. Bhattacharya K. Investigation and management of the hepatic glycogen storage diseases. Trans1 Pediatr 2015;4:240-8.

3. Moses SW, Wanderman KL, Myroz A, Frydman M. Cardiac involvement in glycogen storage disease type III. Eur J Pediatr 1989;148:764-6.

4. Tada H, Kurita T, Ohe T, Shimomura K, Ishihara T, et al. Glycogen storage disease type III associated with ventricular tachycardia. Am Heart J 1995;130:911-2.

5. Humbert M, Labrune PH, Simonneau G. Severe pulmonary arterial hypertension in type 1 glycogen storage disease. Eur J Pediatr 2002;161:S93-6.

6. Humbert M, Labrune P, Sitbon O, Le Gall C, Callebert J, et al. Pulmonary arterial hypertension and type-I glycogen-storage disease: the serotonin hypothesis. Eur Respir J 2002;20:59-65.

7. Derks TG, van Rijn M. Lipids in hepatic glycogen storage diseases: pathophysiology, monitoring of dietary management and future directions. J Inherit Metab Dis 2015;38:537-43.

8. Rake JP, Visser G, Labrune P, Leonard P, Ullrich K, et al. Glycogen storage disease type I: diagnosis, management, clinical course and outcome. Results of the European Study on Glycogen Storage Disease Type I (ESGSD I). Eur J Pediatr 2002;161:S20-S34.

9. Greenea HL, Swift LL, Knapp HR. Hyperlipidemia and fatty acid composition in patients treated for type IA glycogen storage disease. J Pediatr 1991;119:398-403.

10. Fernandes J, Alaupovic P, Wit JM. Gastric drip feeding in patients with glycogen storage disease type I: its effects on growth and plasma lipids and apolipoproteins. Pediatr Res 1989;25:327-31.

11. Bandsma RH, Smit GP, Kuipers F. Disturbed lipid metabolism in glycogen storage disease type 1. Eur J Pediatr 2002;161:S65-9.

12. Bandsma RH, Prinsen BH, van Der Velden Mde S, Rake JP, Boer T, et al. Increased de novo lipogenesis and delayed conversion of large VLDL into intermediate density lipoprotein particles contribute to hyperlipidemia in glycogen storage disease type 1a. Pediatr Res 2008;63:702-7.

13. Sever S, Weinstein DA, Wolfsdorf J, Gedik R, Schaefer EJ. Glycogen storage disease type 1a: linkage of glucose, glycogen, lactic acid, triglyceride, and uric acid metabolism. J Clin Lipidol 2012;6:596-600.

14. Carvalho PM, Silva NJ, Dias PG. Glycogen storage disease type 1a - a secondary cause for hyperlipidemia: report of five cases. J Diabetes Metab Disord 2013;12:25.

15. Bernier AV, Sentner CP, Correia CE, Theriaque DW, Shuster JJ, et al. Hyperlipidemia in glycogen storage disease type III: effect of age and metabolic control. J Inherit Metab Dis 2008;31:729-32.

16. Zhang PY, Xu X, Li XC. Cardiovascular diseases: oxidative damage and antioxidant protection. Eur Rev Med Pharmacol Sci 2014;18:3091-6.

17. Wittensteina B, Kleina M, Finckha B, Ullrich K, Kohlschütter A. Plasma antioxidants in pediatric patients with glycogen storage disease, diabetes mellitus, and hypercholesterolemia. Free Radic Biol Med 2002;33:103-10.

18. Bernier AV, Correia CE, Haller MJ, Theriaque DW, Shuster JJ, et al. Vascular dysfunction in glycogen storage disease type I. J Pediatr 2009;154:588-91. 
19. Bernier AV, Correia CE, Haller MJ, Theriaque DW, Shuster JJ, et al. Vascular dysfunction in glycogen storage disease type I. J Pediatr 2009;154:588-91.

20. Ubels FL, Rake JP, Slaets JP, Smit GP, Smit AJ. Is glycogen storage disease 1a associated with atherosclerosis? Eur J Pediatr 2002;161:S62-4

21. Yekeler E, Dursun M, Emeksiz E, Akkoyunlu M, Akyol Y, et al. Prediction of premature atherosclerosis by endothelial dysfunction and increased intima-media thickness in glycogen storage disease types Ia and III. Turk J Pediatr 2007;49:115-9.

22. Goulart JM, Yoo JY, Kirchoff-Torres KF, Delman BN, Tuhrim S. Ischemic stroke in an adult with glycogen storage disease type I. J Clin Neurosci 2010;17:1467-9.

23. Boudjemline AM, Petit F, Buron HA, Eberschweiler TP, Gajdos V, et al. Glycogen storage disease type I (GSD I). Atlas Genet Cytogenet Oncol Haematol 2012;16:860-3.

24. Goldberg RB. Hyperlipidemia and cardiovascular risk factors in patients with type 2 diabetes. Am J Manag Care 2000;8:S682-91

25. Jeppesen J, Hein HO, Suadicany P, Geintellberg F. Triglycerides concentration and ischaemic heart disease: an eight-year follow-up in the copenhagen male study. Circulation 1998;97:1029-36.

26. Austin MA, Hokanson JE, Edvards KL. Hypertriglyceridemia, as a cardiovascular risk factor. Am J Cardiol 1998;81:7B-12. 